\title{
Recovering the Relational Starting Point of Compassion Training: A Foundation for Sustainable and Inclusive Care
}

\author{
Paul Condon ${ }^{1}$, John Makransky ${ }^{2}$ \\ ${ }^{1}$ Department of Psychology, Southern Oregon University, condonp@sou.edu \\ ${ }^{2}$ Department of Theology, Boston College, john.makransky@bc.edu \\ in press, Perspectives on Psychological Science
}

\begin{abstract}
Cultivation of compassion through meditation training is of increasing interest to scientists, healthcare providers, educators, and policy makers as an approach to help address challenging personal and social issues. Yet people encounter critical inner psychological barriers to compassion that limit the effectiveness of compassion training - including the lack of a secure base, aversion to suffering, feeling alone in suffering, and reductive impressions of others. These barriers emerge, in part, from a lack of relational support and are exacerbated by modernist conceptions that present meditation as an autonomous, self-help practice. This article proposes a solution centered on relationality, derived from the integration of diverse areas of psychology with contemplative traditions. Theories and findings from social, developmental, and health psychology can inform meditation programs and help recover important relational elements of compassion training from traditional cultures that address common barriers to compassion, and thus promote more sustainable and inclusive care. In so doing, this paper illustrates the value of psychological theories for translating important contextual elements from contemplative traditions into diverse modern settings.
\end{abstract}

\section{Key words}

meditation, compassion fatigue, burnout, attachment theory, Buddhism and science

Compassion is a caring attitude toward a person or group by someone who is aware of their suffering and wants to alleviate it. It has been proposed that the cultivation of compassion through meditation training could help address many problems, including burnout in human service and healthcare, bullying in schools, prejudice and discrimination, and to help combat the ongoing ecological crisis (e.g., Jinpa, 2015; Ricard, 2015). Empirical research suggests that compassion meditation trainings yield important benefits, including increased psychological wellbeing (Shonin, Gordon, Compare, Zangeneh, \& Griffiths, 2015), adaptive physiological and behavioral responses to stress (Jazaieri et al., 2013, 2014; Pace et al., 2009, 2013) and prosocial behavior (Condon, 2017, 2019). Yet several inner psychological obstacles limit people's ability to experience and cultivate compassion, including the lack of secure attachment (Mikulincer \& Shaver, 2005), aversion to suffering (Batson, 2011; Klimecki, Leiberg, Ricard, \& Singer, 2014), a sense of feeling alone in suffering (Maslach, Schaufeli, \& Leiter, 2001), and reductive perceptions of self and others (Cikara, Bruneau, \& Saxe, 2011). Moreover, structural barriers and systemic inequalities pose further challenges to compassion and care (e.g., Dev, Fernando, Kirby, \& Consedine, 2019; King \& Wheeler, 2004).

In our view, sustainable and inclusive compassion that overcomes these barriers emerges from a communal and relational field of caring support. By "sustainable compassion," we mean the ability to return to a strong secure base as needed for replenishment, which recurrently supports reengagement with compassionate activity under challenging circumstances. We hypothesize that such a sustainable power of compassion can help 
people in caring roles avoid mental depletion, compassion fatigue, and burnout. We use the term "all-inclusive," and its shortened form "inclusive," with the usual sense of including everyone within the scope of care and compassion. One who experiences what it is like to be seen as worthy of care and supported in care can develop the inner core of security needed to see and relate to others similarly with increasing sustainability, inclusivity and unconditionality. We call this the relational starting point for cultivating care and compassion.

Western meditation programs have neglected the relational starting point that has been assumed as the basis for compassion training in prior contemplative cultures. In traditional Buddhist practices, for example, a person first learns to experience themselves as encompassed within the care and compassion of their spiritual community (Makransky, 1998, 2011, 2012a). To train in allinclusive care and compassion, then, is to learn to participate in that community by learning to extend the same care and compassion to others. Research throughout social, developmental, and health psychology affirm the profound necessity of relationality for physical health, well-being, and sustainable caregiving. In this article, we explore why modern meditation programs lost the relational starting point for cultivating care and compassion, we explore barriers to compassion that arise without a relational field, and we describe forms of relational practice found in traditional Buddhist cultures. Finally, we present a model of relational compassion training that is informed both by the relational training patterns of those cultures and by modern psychological science. This model aims to promote sustainable and inclusive care in forms that are adapted for modern contexts.

\section{The Absence of the Relational Starting Point in Western Meditation Programs}

Western meditation practices emerged through the lens of a modernist framework in the late $19^{\text {th }}$ century when western theoretical discourses and cultural practices gave rise to an increasing sense of individualism (McMahan, 2008; Thompson,
2020). In this cultural context, meditation was adapted and construed within a self-help framework in which individuals, through their own efforts, could remake themselves into more mindful or compassionate persons. Any Buddhist element that did not easily fit into the framework of individualistic self-help was filtered out of most meditation trainings (Purser, Forbes, \& Burke, 2016).

Several threads of western modernity contributed to a vision of people as separable from and existing before relationships. As McMahan states, people conditioned by western modernity tend to hold an anthropological view of people as possessing "distinct identities, ontologically prior to social groups and relations." (McMahan, 2008, p. 196, emphasis added). Many cultural trends bolstered this view: Protestant religion exalted the spiritual authority of individual experience and a relationship with God unmediated by institutional structures such as a church or a religious figure; political discourse such as liberal social theory emphasized the rights and freedoms of individuals; and psychoanalysis offered a technique to free oneself from the neuroses that had resulted from suppressing one's desire to fit social expectations (McMahan, 2008). With this cultural milieu established, influential early western adopters of Buddhism and some Asian Buddhist ambassadors to the West portrayed meditation in novel ways that reinforced implicit expressions of individualism. Yet this individualistic, non-relational approach to meditation is unrecognizable within traditional Buddhist practice, precisely because it lacks the relationality assumed as an entry point to Buddhist practice.

Many of the foundational practices in traditional Buddhist communities include relational elements embedded in ritual practices of refuge, devotion and service to community. Relational elements include taking refuge-in other words, finding a safe place-in the love, compassion and wisdom embodied by Buddhas, bodhisattvas, teachers, and other accomplished practitioners (sangha), offering service to them, and receiving their blessings. These practices form a basis for generating a similar power of love, 
compassion and wisdom that would encompass many other beings. Through the lens of modernism, these devotional-relational practices were perceived as superstitious or mythological accidents or "accretions" of Asian culture. Moreover, these "cultural accretions" have been perceived as deviations from the original essence or core teachings of the Buddha, which were construed through a modernist lens as more exclusively rationalistic and individualistic (McMahan, 2008, refers to this analysis as the "core-versus-accretions" model). Devotional, relational, and communal practices thus received little or no attention in the western adaptation of meditation programs and in the corresponding scientific research on those programs.

For a traditional Asian Buddhist practitioner, relational practices serve a critical function for the maximal development of wisdom, love, and compassion. Devotion and refuge provide a context in which Buddhists experience themselves as deeply relational beings. Their efforts to cultivate wisdom, love, and compassion involve experiencing themselves in an all-inclusive scope of care from a lineage of teachers, saints, and community envisioned before them that have taken up Buddhist practice and realized qualities of inclusive and unconditional compassion. In essence, practitioners learn to become an extension of the field of care in which they are held: to love others as they are loved, to know others as they are known, to hold others in the wisdom and compassion in they are held by their spiritual community. In this way, refuge and devotion serve as an unlimited and unwavering foundation (i.e., a secure base) from which a Buddhist practitioner can engage in difficult, extensive meditation practice and extend allinclusive care to others.

The concepts of refuge and devotion pose clear challenges for modern western culture. To ask a Westerner to take refuge in teachers, family, and community could prove difficult due to cultural values or past traumas. The rise of modernity centered on increasing individualism and a growing mistrust in society, institutions, community, and family. The shift toward privatized religion leaves the individual free to adapt and make use of any element of a tradition she so chooses. Yet the very notion of an individual engaging in meditation practice as a means to grow in capacities of love, wisdom, and compassion through her own efforts can ironically reinforce that which Asian Buddhists have always aimed to transcend: the notion of an autonomous, separate, enduring self. In turn, barriers to inclusive and sustainable compassion may be exacerbated by the modernist concept of meditation as individual self-help. In the following sections, we explore psychological barriers to compassion that are reinforced by the modernist lack of relationality, and examine how theories and data from developmental, social, and health psychology can help recover the relational starting point of compassion training in modern settings.

\section{Barriers to Compassion Without the Relational Starting Point}

Humans come prepared, through evolution, with innate capacities for empathy and compassion (Gilbert, 2019; Goetz, Keltner, \& Simon-Thomas, 2010; Hrdy, 2009), but these capacities become attenuated in predictable patterns, especially when suffering is encountered repeatedly or under other challenging circumstances including past traumas (Kirby, Day, \& Sagar, 2019). Barriers to compassion include a number of psychological processes that arise from a lack of relationality: 1) the lack of an adequately secure base (Mikulincer $\&$ Shaver, 2005), 2) aversion to suffering (Batson, 2011; Klimecki et al., 2014), 3) feeling alone in the experience of suffering (Maslach et al., 2001), and 4) reductive perceptions of others (Cikara et al., 2011). In this section, we explore these four barriers to compassion through the lens of attachment theory, which demonstrates how a lack of relationality exacerbates those barriers. While our review focuses on the inner psychological barriers to compassion, we also acknowledge the presence of systemic inequities that interact with and reinforce these inner barriers (cf., Wilkinson \& Pickett, 2020). We return to a consideration of systemic inequities in the conclusion of the paper. 
Barrier 1: Lack of an adequately secure base. Attachment theory links infants' experiences with early caregivers to the subsequent development of interpersonal capacities through adulthood, including selfefficacy, curiosity, empathy, courage, compassion, and prosocial behavior (Feeney \& Collins, 2019; Mikulincer \& Shaver, 2005; Shaver, Mikulincer, \& Cassidy, 2019; Shaver et al., 2016). In times of distress, infants seek to maintain proximity to and solicit care from caregivers, primarily through vocal and facial cues of distress. Responsive and supportive caregivers foster a sense of security within infants, engendering a sense of self that is worthy of love, such that provision of care becomes the default expectation. Security also supports confidence to explore and pursue novelty that could involve vulnerability, including the extension of care to others. Care that is sporadic or contingent fosters a sense of insecurity within infants - that care is not always available and is not unconditional. In short, sensitive and responsive care for others is facilitated by the experience of having received care from supportive others (Feeney \& Collins, 2019).

A key feature of attachment theory is that even people with secure attachment histories can have traces of insecurity, which can be activated by actual or imagined encounters with unsupportive others (Holmes \& Slade, 2018; Mikulincer \& Shaver, 2007, 2015). Similarly, people with predominately insecure attachment histories can experience feelings of security with particular support figures despite the lack of secure attachment with a primary caregiver (Brown \& Elliott, 2016; Kobak, Zajac, \& Madsen, 2016; Mikulincer \& Shaver, 2007, 2015). Each person likely has a general attachment orientation but also a complex network of attachment representations that encode experiences with specific people, relationships, or other relational contexts or communal and organizational contexts (Collins \& Read, 1994). In our view, barriers to compassion arise when feelings of insecurity are activated, including for highly secure people. The goal of all-inclusive, increasingly unconditional, and sustainable compassion thus requires an unlimited secure base-one that can be drawn on in times of stress, hostility, and neverending encounters with suffering. An unlimited secure base, then, is one that is always available and experienced as an enduring, unconditional, and completely reliable source of loving qualities, which need not be limited to a single attachment figure. Later in this article, we explore how contemplative practice can help people access and strengthen the felt sense of an unlimited secure base.

Early relational experiences form the basis for internal working models of self, other, the world, and relationships (Bretherton \& Munholland, 2016), which include implicit expectations of what it is like to be in relation with and how to respond to others (H. S. Waters \& Waters, 2006; T. E. Waters \& Roisman, 2019). These internalized messages are often subconscious and become operative, automatically, in any moment of emotional connection with others. Moments of emotional intimacy or care thereby trigger a variety of internal working models. These models then impact a person's capacity to regulate emotion, abilities to feel compassion, and behavioral responses to a situation (Bretherton \& Munholland, 2016; Shaver et al., 2019). Empirical findings confirm that feelings of insecurity are associated with reduced compassionate responsiveness to others' suffering (Cassidy, Stern, Mikulincer, Martin, \& Shaver, 2018; Mikulincer \& Shaver, 2005). Individuals who lack a felt sense of security in the moment were less likely to engage in costly helping behaviors for others in need-a pattern that has been replicated across experimental and correlational designs in the context of care for close relationship partners (Feeney \& Collins, 2001) and single-shot helping scenarios with strangers (Mikulincer, Shaver, Gillath, \& Nitzberg, 2005). These findings illustrate that compassionate actions are best supported by the foundation of a secure base-in other words, a relational field of support.

In a similar line of research, insecure attachment patterns are associated with fears of compassion (Gilbert, McEwan, Matos, \& Rivis, 2011; Kirby et al., 2019). Fears of compassion can include a fear of losing one's poise, fear of being rejected or ineffective in care for another, fear 
that others will take advantage of kindness, and fear of extending compassion to another that does not deserve it. Moments of receiving compassion can also trigger memories of wanting but not receiving affection and care, an awareness of inner loneliness, or yearning for close and accepting relationships (Gilbert et al., 2011; Kirby et al., 2019). If contemplative practices helped people internalize an unlimited secure base, it could help mitigate these fears.

Barrier 2: Aversion to suffering. A second barrier to compassion emerges when people experience empathic distress - an aversive feeling upon encountering others' suffering that is highly arousing and associated with self-focused worries (Batson, 2011; Klimecki et al., 2014). Feelings of empathic distress can elicit either avoidance or egoistic helping, such as motivations to remove one's own unpleasant feelings by improving another's state (Batson, 2011; Eisenberg \& Miller, 1987). Moreover, repeated experiences of empathic distress can lead to secondary trauma and compassion fatigue (Rothschild, 2006), which contributes to high rates of burnout in many service professions, including teachers, healthcare workers, mental health providers, and clergy (Paris \& Hoge, 2010). Distress in response to others' suffering thus poses a pervasive barrier to sustainable and inclusive compassion.

Feelings of insecurity are a known risk factor for empathic distress. Those with insecure attachment orientations, for example, experience difficulties with emotion regulation and thus become distressed upon encountering others suffering. Alternatively, feelings of insecurity combined with empathic distress can yield compulsive caregiving, in which caregiving is a strategy for satisfying personal unmet needs for social connection, approval, and reassurance. Corresponding caregiving efforts may be insensitive, intrusive, or chaotic (Feeney \& Collins, 2019; Shaver et al., 2019). Meanwhile, those with a secure attachment orientation are more likely to respond and help others in a more sensitive, other-focused manner (Shaver et al., 2016). Nevertheless, if there is a failure to provide sufficient resources and a supportive community at an organizational level, insecurity is often fostered among individuals, which contributes to distress and ultimately burnout (Maslach, Schaufeli, \& Leiter, 2001; Ronen \& Mikulincer, 2012).

In addition to aversive feelings of distress and insecurity, recent research has explored why people experience aversion to suffering, particularly when confronted with the suffering of people on a mass scale (Cameron, 2017) or upon encountering stigmatized others (Cameron, Harris, \& Payne, 2016). People appear to make a motivated choice to avoid empathy for other's suffering when they anticipate empathy to be too costly and effortful (Cameron \& Payne, 2011; Cameron et al., 2019). People strategically avoid empathy and compassion just when more is needed.

In addition to concerns about emotional exhaustion and effort, when people think that they lack the efficacy to address others' needs, they choose to avoid empathic engagement (Cameron et al., 2019). In contrast, increased confidence in one's ability to empathize and meet others' needs enhances empathic engagement (Cameron et al., 2019; Lim \& DeSteno, 2019; Sharma \& Morwitz, 2016). Also, the belief that empathy is a skill that can grow through one's efforts increases people's willingness to empathize when it is challenging (e.g., toward a member of an out-group; Schumann, Zaki, \& Dweck, 2014). If people believe their efforts to engage and care for others will be effective, and that they can actively increase their abilities to empathize with others, they are more likely to make the active choice to engage with other's suffering. ${ }^{1}$

The role of efficacy in overcoming aversion to suffering is centrally aligned with our theorizing the need for a relational starting point. As noted with Barrier 1 above, a key feature of security is the courage and self-efficacy to explore one's environment and connect with others, which could also support one's ability to be with another's suffering without experiencing empathic distress. This perspective dovetails nicely with Social Baseline Theory (SBT; Beckes \& Coan, 2011; Coan \& Sbarra, 2015), which suggests that people serve as a bioenergetic resource for each other. That is, the mere presence of a supportive 
person is sufficient to reduce one's reactivity to threat. In line with SBT, we hypothesize that an unlimited secure base will support more unlimited and all-inclusive compassion even during times of distress and empower one's ability to become present to others who are suffering in a comforting and salubrious way even prior to any effort to actively change their situation.

Barrier 3: Feeling alone in suffering. For many people, the experiences of suffering and the difficulty of caring for another's suffering are isolating. In many service professions that require ongoing compassionate care of others, for example, the perception of being alone in the difficulties of such work results in exhaustion and burnout, leading to emotional disengagement and ineffective care for others (Maslach et al., 2001). When people take on caregiving roles without social support, the role can be felt as obligatory and thus have detrimental effects on the caregiver's physical health (Vitaliano, Zhang, \& Scanlan, 2003). On the other hand, caregiving is experienced as nourishing when social support is present (Brown et al., 2009), suggesting that feeling alone in such roles is a key obstacle to sustainable compassion.

A key characteristic of felt insecurity is a perception of isolation, even when care and connectivity are available. People with insecure attachment are less likely to perceive social support when it is happening (Collins \& Feeney, 2004) and they are more likely to see threats in the environment that may not exist (Dykas \& Cassidy, 2011; Mikulincer \& Florian, 1995). People with insecure attachment are less likely to seek out social support and participate in community building in times of great need. A primary characteristic of avoidant attachment is ineffective support-seeking when distressed, for example, using indirect requests for help such as hinting, complaining, sulking, and fidgeting, rather than direct emotional disclosure and request for help (Collins \& Feeney, 2000). These patterns suggest that insecurities prevent capitalization on social connections, which in turn decreases the likelihood of resilience and upward cycles of compassion (Lim \& DeSteno, 2016).
Psychological rigidity also contributes to the experience of feeling isolated in one's suffering as an objective reality. Cognitive fusion and reification create the impression of objective reality out of subjective constructions (Bernstein et al., 2015; Hayes, 2004; Lutz, Jha, Dunne, \& Saron, 2015). Cognitive fusion is the fusion of a mental representation with some aspect of reality. Reification is mistaking one's mental representation for reality. These processes support rigid thought patterns that underlie rumination and mental health symptoms such as depression and anxiety. Moreover, the ability to notice thoughts without identifying with themcalled dereification, decentering, or defusionfosters mental health (Bernstein et al., 2015; Hayes, 2004; Lutz et al., 2015). Psychological rigidity reifies suffering, thus occluding the possibility of noticing social support or one's own capacities and potential to meet difficult situations with compassion. Rigidity reinforces the inability to recognize one's own layers of suffering as a possible basis of empathetic connection with others in their layers of suffering (cf. Lim \& DeSteno, 2016). Moreover, psychological rigidity likely reinforces each of the other barriers by inhibiting the experience of relationality and by reifying feelings of aversion, lack of efficacy, and reductive impressions of others.

Barrier 4: Reductive impressions of others. Research reveals the readiness with which the mind engages in stereotyping, prejudice, and discrimination in intergroup contexts. Social identity theory suggests that social relations play an integral role in people's construction of their own identity (Tajfel \& Turner, 2004), which can bolster in-group favoritism and reduce prosocial tendencies toward members of out-groups (Cikara, Bruneau, Van Bavel, \& Saxe, 2014). Arbitrary group identities shape not only attitudes and preferences, but also basic perception of others (Van Bavel, Packer, \& Cunningham, 2008). In-group biases also foster dehumanization of members of an out-group (Waytz \& Epley, 2012). Reductive biases thus comprise a barrier to more inclusive compassion.

Restrictions on compassion and empathy also occur even with regard to members of one's in- 
group, especially when one loses touch with a secure base. Attachment-based experiences are one manner in which identity is formed through relationships, which shape processing of subsequent social information (Baldwin, 1992; Dykas \& Cassidy, 2011). In interactions with close relationship partners, for example, people with insecure attachments have lower thresholds for emotional dysregulation and are more likely to behave in a hostile or dismissive manner during difficult conversations (Simpson, Rholes, \& Nelligan, 1992). Reductive impressions of others are thereby indicative of activated insecurity in oneself.

A pernicious feature of human cognition stems from the tendency to attribute an underlying essence to constructed categories, such as race, gender, and social hierarchies-known as psychological essentialism (Mandalaywala et al., 2018). Psychological essentialism involves grouping two or more instances together on the assumption that they share a common cause and core features that make them fundamentally identical. This reified perception of unchanging identity unifies all instances of a category, causing people to perceive the commonalities between instances of a category while ignoring the differences (Gelman, 2004). Reified reductive impressions that are fostered by psychological essentialism stand as a subtle but all-pervasive barrier to compassion by causing one to mistake reductive concepts of persons for the persons, thereby losing contact with their fuller humanity, dignity, and unconditional worth which would foster care and compassion for them all. As discussed below, the internalization of an unlimited secure base can support the ability to see past reductive impressions of others.

\section{Relationality Addresses Each Barrier to Compassion}

Data throughout social, developmental, and health psychology consistently reveal that humans flourish when nested within stable and supportive social networks and relationships, and that relationality helps overcome each of the barriers to compassion noted above. Research on attachment priming suggests that feelings of security can be temporarily enhanced, and that such feelings can help people overcome the barriers noted above (Gillath \& Karantsaz, 2019). In attachment priming studies, participants are temporarily exposed to pictures, words, or imagery that evoke a felt sense of security, such as a picture of a caring person or simple phrases that connote safety and security. Based on the results from these studies, we hypothesize that much greater repetition of connection with the experience of a secure base, through contemplative training, could further establish the unlimited core of security needed to overcome barriers to compassion. That is the kind of training that can help recover the relational starting point of meditation assumed in traditional Buddhist cultures that has often been dropped in western meditation programs.

A number of key findings illustrate the benefit of social connection. The physical presence of a supportive relationship partner heightens emotion regulation capacity, as demonstrated by attenuated neural responses to threat (Coan, Schaefer, \& Davidson, 2006) and enhanced cardiovascular recovery to stress (Allen, Blascovich, Tomaka, \& Kelsey, 1991). People with social support not only recover from stress more effectively in their emotional lives, but their bodies recover from illness more quickly (Cohen, 2004; Pietromonaco, Uchino, \& Dunkel Schetter, 2013). Social support is also associated with lower inflammation and decreased risk for mortality (Ehrlich, Miller, \& Chen, 2016; Holt-Lunstad, Smith, \& Layton, 2010). Caregivers experience their roles as nourishing when they have a sense of social support (Brown et al., 2009). Moreover, on the communal level, communities characterized by social connection feel more prepared for disaster (Cagney, Sterrett, Benz, \& Tompson, 2016). As such, people with social support have greater resilience and emotion regulation capacities, allowing them to meet suffering with compassion rather than distress.

The findings above are based on the physical presence of supportive social connections in daily life. Yet the psychological availability of others need not be restricted to physical proximity. An 
important feature of attachment theory is that feelings of security can be augmented even among people who have an insecure orientation, and attachment patterns and orientations can change over time (Mikulincer \& Shaver, 2015). Nearly two decades of research on attachment priming demonstrates that subliminal and supraliminal priming in the form of pictures, words, sentence completion tasks, and guided imagery can be used effectively to reconnect people with moments of security, thereby shifting their attachment level to greater security temporarily (for reviews see Gillath \& Karantzas, 2019; Gillath, Selcuk, \& Shaver, 2008; Mikulincer \& Shaver, 2007, 2015). Attachment priming yields numerous benefits to emotion regulation and interpersonal processes. Moreover, these benefits typically are not moderated by participants' history of security or insecurity (Mikulincer \& Shaver, 2007, 2015).

Of great importance, simple moments of security activated through attachment priming are sufficient to momentarily reduce each of the barriers to compassion reviewed above. Data show that attachment priming causes people to become more resilient to threat and better able to regulate emotions (Norman, Lawrence, Iles, Benattayallah, \& Karl, 2015), to exhibit compassion even for larger numbers of people who are suffering (Kogut \& Kogut, 2013), and to overcome mental fatigue while others are disclosing emotional information (Mikulincer, Shaver, Sahdra, \& Bar-On, 2013). These effects also extend to the body and brain: the mere mental activation of supportive social connections reduces cardiovascular reactivity to stress (Smith, Ruiz, \& Uchino, 2004), pain-related neural activity (Eisenberger et al., 2011), and neural responses to social exclusion (Karremans, Heslenfeld, van Dillen, \& Van Lange, 2011). Attachment priming also reduces prejudice and hostility toward outgroups (Boag \& Carnelley, 2016; Mikulincer \& Shaver, 2001). Finally, although some research suggests that connection with an in-group facilitates dehumanization of others (Waytz \& Epley, 2012), priming security and nurturance reduces dehumanization (Zhang, Chan, Teng, \& Zhang, 2015). Though attachment priming effects do not yield permanent dispositional changes, their effects can last up to 10 days following the priming manipulation (Gillath et al., 2008). Attachment priming points to the possibility of more rigorous training for compassion.

The findings just reviewed are encouraging, but there are limits to attachment priming, which suggest the need for more systematic training that extends one's sense of secure base. Studies show that subliminal attachment priming is not sufficient to overcome self-worth threats, which subsequently interfere with responsiveness to distress in others (Mikulincer, Shaver, Bar-On, \& Sahdra, 2014). It may be that threats to self-worth, activated by thoughts of social rejection, interfered with attending to another's needs (Shaver et al., 2019). However, there appear to be strengths specifically associated with deliberate guided imagery and visualization in which participants are asked to spend a few minutes visualizing an interaction with a close other of receiving love, comfort, and security. Studies employing this technique have consistently yielded positive affect and emotional well-being and reductions in hostility and prejudice toward out-groups (Gillath \& Karantzas, 2019). These studies suggest the possibility that repetition of attachment-based visualizations within contemplative practice could support the internalization of an unlimited secure base via meditation (cf. Shaver, Lavy, Saron, \& Mikulincer, 2007).

An unlimited secure base may serve two key functions relevant for compassion training: 1) it establishes the secure base needed to feel safe, to be a welcoming presence to others and to be able to extend care to them, and 2) it provides the inner security needed to become compassionately present to all parts of oneself-including destructive relational patterns, defensive reactions, and self-clinging impulses of thought and feeling that contribute to the barriers above. Then one's mind feels safe enough to let all such patterns relax, experienced as healing at an emotional level, which supports greater flexibility and change (cf. Slade, 2016). Ultimately, we hypothesize that an unlimited secure base that has been internalized will foster the capacity to extend sustainable and inclusive compassion to all others. 


\section{Relational and Socially Embedded Compassion Training}

The previous section of this paper points us back to the selection of meditation practices from premodern cultures, which might address modern challenges to compassion in the West. Previous generations of Buddhists who trained in inclusive and increasingly unconditional love and compassion have had a different starting point for such training: not the hyperindividualistic framework of self-help so widely assumed in western meditation programs today, but one of deep relationality-the sense that one is encompassed in the loving care and compassion of other persons, and because of that, one can learn to participate in that same way of relating to many others. Such training was not conceived, as it often is today, as a project of an autonomous self to generate inclusive, sustainable compassion just on one's own, but as a way for a deeply relational self to extend the power of compassion in which oneself is held to many others. In this way, the power of care comes not just from one's own efforts, but also from beyond oneself to inspire and support one's efforts. Practitioners thereby gained confidence in cultivating increasingly unconditional and inclusive care for all, a practice that has always been challenging due to the barriers noted earlier.

A relational starting point of training in love and compassion has been broadly assumed across Buddhist cultures, traditions and periods. In many Pali scriptures, the Buddha enjoins his followers to cultivate all-inclusive attitudes of loving care, compassion, empathetic joy and equanimity that literally encompass all beings (Majjhimanikaya Sutta 7.13-14; see also Suttas 8, 21, 31, 40, 48, 50, 52, 55, 62; Nanamoli \& Bodhi, 1995). Such discourses express a way of practice transmitted through numerous generations of the Buddha's followers. For an Asian Buddhist to hear such a discourse is to understand herself as one of those encompassed in that field of all-inclusive loving care and compassion, by all who have generated those attitudes before her and all who support her in them now. To enter into such a practice is not the action of an individualistic self, who learns on one's own to generate all-encompassing love. Rather, practitioners have understood the practice as a way for them to participate in, and ultimately become an extension of, the field of all-inclusive care that supports them. This has given prior generations of trainees the confidence that they, like those before them, can progress in such a practice, in spite of the kinds of barriers noted earlier. The Buddhist understanding of deep relationality as the foundation of practice is formalized in the notion of refuge, in which the Buddha and accomplished sangha are experienced as embodiments of the all-encompassing forces of love and wisdom that inspire and empower many others to cultivate the same qualities.

A related practice theme is the experience of being seen as deeply worthy of loving care and compassion, an experience evoked, in part, through practices which involve bringing the Buddha and accomplished members of the spiritual community vividly to mind (buddha- and sangha-anusmrti). In the fifth century scholar Buddhaghosa's description, meditators focus their attention on the Buddha's enlightened qualities, which include his all-pervasive, unconditional love and compassion that encompass the meditator and her whole world (Buddhaghosa, 1975). Such practices are further developed in Indian Mahayāna scriptures, where fields of buddhas and bodhisattvas are envisioned directly in front, gazing into the deep dignity and capacity of the meditator's enlightened potential and into the destructive patterns of thought and reaction that obscure it (e.g., Śāntideva, 1997, pp. 51-86; McMahan, 2002, pp. 149-174). The experience of being deeply seen and encompassed in unconditional compassion and wisdom also informs the notion of empowerment in Vajrayana (tantric) traditions of South Asia and Tibet. The Vajrayana teacher's perception of the students' enlightened potential communicates itself through ritual forms that resonate with that potential in the students, empowering them to begin to transcend their reductive perceptions of themselves and others by joining in the deeper seeing by which they are seen (dag snang, pure perception). 
The deeply relational mode of practice just described can be understood to undercut the first barrier to compassion, lack of a sufficiently secure base, by establishing an unlimited secure base, which supports an unlimited extension of compassion to others. This mode of practice also seems to undercut the second barrier to compassion-aversion to suffering-by experiencing all suffering as embraced in the care and compassion made present by the relational field. This view is consistent with the growing awareness that communities and group settings are necessary to foster support for challenges that arise during contemplative practice (Treleaven, 2018, pp. 150-176). The relational mode of practice undercuts the third barrier-feeling alone and isolated in one's suffering-by keeping the practitioner connected to an ongoing source of support and replenishment. The relational mode practices should also foster a practitioner's efforts to seek out social support and community building. Such community building would also support individuals in their ongoing meditation practice and in efforts to heal from and challenge systems of inequity. Finally, relational practices should provide the secure base needed to support a recognition of common humanity, dignity, and worth in all others that transcends one's reductive impressions of others. This undercuts the fourth barrier to compassion.

All the Buddhist practices described above are forms of meditation training. One important advantage of meditation training in love and compassion compared with attachment priming is that meditation involves a tremendous amount of repetition over time-e.g., repeatedly reinhabiting and settling more fully into the experience of love, safety, being seen, acceptance, and comfort evoked by recalling a field of compassionate connection. Relational meditations support the internalization of an unlimited secure base by recalling a moment of secure, caring connection in daily practice, and then repeatedly reinhabiting that experience in brief moments throughout the day. Over months of practice, one will have repeated this experience of secure attachment thousands of times. Indeed, the foundational meditation practices of traditional Tibetan training involve repeatedly reinhabiting a spiritual field of secure attachment like those described above at least one hundred thousand times, in order to establish the unlimited secure base necessary for all other practices, such as further training in compassion and wisdom (Samuel, 2012, pp. 8083). The theories and findings reviewed in this paper suggest it would be beneficial to reestablish a relational starting point in modern cultures for meditation training in compassion. We discuss one model of this approach in the subsequent section.

\section{Adapting the Relational Starting Point of Traditional Buddhism for Secular Application}

The relational starting point for compassion training can be adapted for modern accessibility from traditional patterns of practice, informed by the theories and research findings reviewed in this paper. One such program is "Sustainable Compassion Training" (SCT; also called "Innate Compassion Training", Makransky, 2019), which provides access to one's innate human capacity for care and compassion first by recalling a simple moment of caring connection from any time in one's own life, with any person or being, then by reinhabiting that moment to re-experience oneself as seen and loved within it. This mode of meditation practice is called the "receptive mode" of SCT (Makransky, 2007, 2011; for reviews comparing SCT with other contemplative programs, see Lavelle, 2016, 2017; Roeser, Colaianne, \& Greenberg, 2018). By reinhabiting a moment of caring connection repeatedly, the practitioner increasingly strengthens her secure base while learning to accept her worth and potential beyond reductive labels of self. This empowers her to see others similarly in their worth and potential beyond reductive labels and extend care and compassion to them. With repetition, more moments of caring connection are recalled, and a relational field of caring moments and figures can emerge analogous to what has been envisioned in traditional cultures of training. With familiarization through repetition, one thereby learns to experience feelings, including suffering feelings of self and others, as 
Figure 1. Sustainable Compassion Training meditations and their functions

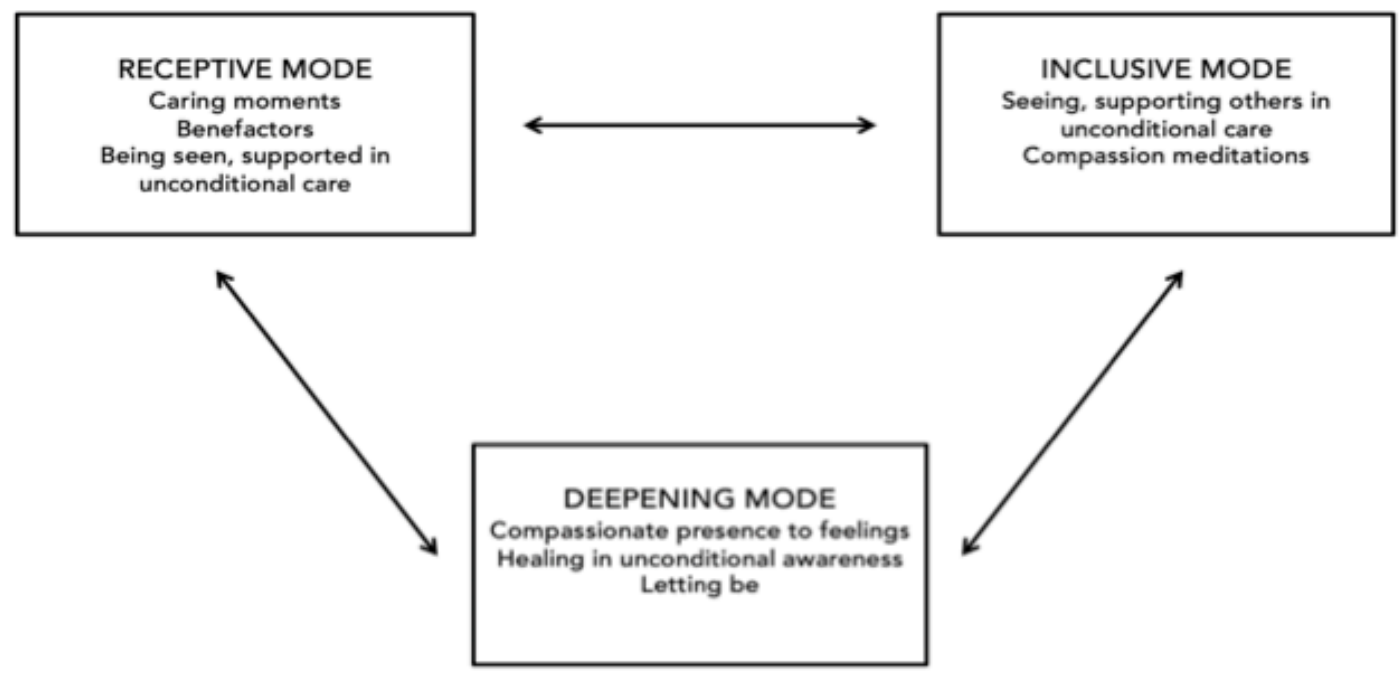

Hypothesized functions of each mode in Sustainable Compassion Training

- Receptive mode: Establish and strengthen outer secure base by inhabiting a relational field of care; experience being seen and supported as unconditionally worthy; access one's inner capacity for caring qualities.

- Deepening mode: Access inner, unlimited secure base of openness and warmth for replenishment and healing; become compassionately present to all layers of thought and feeling; release ingrained habits of reductive thought and reaction.

- Inclusive mode: See and support others as unconditionally worthy; extend increasingly sustainable and inclusive compassion to others beyond reductive impressions; reconnect with your own outer and inner secure bases as needed for replenishment.

encompassed in a spacious field of care and compassion that can heal and transform them, rather than as objects to push away, fix, or defend against (see Figure 1 for a diagram of SCT practices and their functions).

A common challenge to the caring moment practice arises when people struggle to immediately identify a caring moment. A feature of insecure attachment includes internal working models that dismiss moments of connection or care from others (Dykas \& Cassidy, 2011; Mikulincer \& Florian, 1995). Thus some people might at first struggle to connect with this practice. Our emphasis is on a simple moment of caring connection that can take diverse forms, including the feeling of care that comes from recalling a caring moment with any individual, such as a beloved mentor, relative, teacher, friend, a caring stranger, a cherished pet, or from recalling one's ancestors, a special place, or an inspiring figure, such as a poet, writer, or spiritual figure. Caring moments could also be those in which the practitioner himself extended care to another, or observed a moment of care between other people that made him feel joyful (similar to the feeling of moral elevation; Schnall, Roper, \& Fessler, 2010). In this way, practitioners are invited to fill in the content of the meditation in a form that is most accessible to them.

An important feature of receptive mode practices is their consistency with current perspectives on grounded and situated cognition (Barrett, 2017; Barsalou, 2008, 2016). According to theories of grounded cognition, episodic memories and conceptual knowledge are simulated and re-enacted throughout multiple systems in the brain (e.g., motor, visual, kinesthetic, interoceptive, affective, perceptual). During the caring moment practice, practitioners visualize and simulate a felt sense of security by feeling into a caring moment as if it is happening in the present (not as a distant memory), while noticing the felt qualities of care, love, warmth, acceptance, safeness, being seen, peace etc. that comes with that moment. These practices, then, are not merely aspirational, but connect the 
practitioner with an embodied, affective experience of relationality by simulating and reenacting relevant systems and conceptual knowledge in the brain and body.

When the practitioner has become familiar with the receptive mode of meditation, she enters into the inclusive mode, not as a non-relational self trying to make herself more loving on her own, but as someone supported by a field of care and compassion, who is learning to extend the same perspective, energy and attitude of care in which she is held to others in widening circles of inclusion. It is by returning repeatedly through contemplative practice to the field of care in which she is held and deeply seen that she is empowered to see and hold others similarly in their dignity and potential, beyond any reductive impressions, analogous to the relational training in Buddhist traditions of origin. ${ }^{2}$

Both of these contemplative modes, the receptive mode and inclusive mode, support and are supported by a third contemplative mode called the deepening mode. Through the use of aesthetic language in guided meditation, the meditator learns to accept the felt qualities of love and compassion from her secure base into every part of her body and into all her layers of thought and feeling. As her mind more fully experiences and learns to trust those loving qualities, her mind becomes more willing to trust the source of those qualities beyond self-clinging, and to settle with those qualities into their source-the spaciousness, warmth, simplicity, and clarity of her fundamental awareness. Tibetan scholars and teachers refer to this as the most natural or primordial state of awareness (Makransky, 2007, pp. 33-68; Thondup, 1996; Tsoknyi Rinpoche, 2012, pp. 41-80; Varela, 1999). This empowers her mind, through repetition, increasingly to relax and release its ingrained habits of reductive thought and reaction and to settle into the felt sense of inner peace and equanimity available in that basic awareness. Additional deepening mode practices of compassionate mindfulness of feelings and letting be further empower the process of deeply accepting, relaxing into, and releasing reactive patterns of thought and feeling. Deepening mode contemplations enhance the felt sense of secure base that supports the other two modes of contemplative practice by preventing or helping to heal the barriers to compassion training noted earlier. SCT, then, exemplifies one way of establishing a relational starting point for compassion training analogous to that in premodern traditions.

Initial research findings on SCT practices are encouraging. In recent research, SCT practices combined with social-emotional learning were introduced to Israeli and Palestinian 10-year-old children in schools in a partially randomized controlled trial (Berger, Brenick, \& Tarrasch, 2018). Following a 24-week training period that included one weekly session, children indicated greater readiness for social contact with the Israeli or Palestinian out-group, and reduced affective prejudice and stereotyping of out-group children. Moreover, these beneficial results were maintained at six-month follow-up, during a period of violent escalation in the IsraeliPalestinian conflict, while deterioration in intergroup attitudes emerged for the waitlist control group. A similar program for teachers demonstrated increased efficacy, perspectivetaking, and reduced personal distress following training with SCT practices (Tarrasch, Berger, \& Grossman, 2020). In a study of an eight-week compassion training program, receptive mode practices supported other meditations on compassion adapted from Tibetan forms (i.e., lojong, tonglen), which yielded increased prosocial behaviors meant to alleviate another's suffering (Condon, Desbordes, Miller, \& DeSteno, 2013). In a different eight-week study, receptive and inclusive mode practices of SCT yielded faster cardiovascular recovery from anger following an interpersonal provocation compared with a positive psychology discussion control group (Condon, 2014). Guided visualizations that emphasize receiving care have been shown to induce parasympathetic activity and reduce cortisol (Rockliff, Gilbert, McEwan, Lightman, \& Glover, 2008) and reduce social fears and selfcritical thoughts (Gilbert \& Irons, 2004). Though at an inchoate stage, research on these SCTrelated practices suggests the four barriers to compassion can be reduced or overcome with 
support from a relational starting point (Roeser et al., 2018).

The theoretical perspectives and findings reviewed throughout this paper lend support to further hypotheses. In particular, we hypothesize that SCT contemplative practices will promote beneficial outcomes that promote more sustainable and inclusive care, including a growing ability to connect with an inner sense of wellbeing and replenishment in service work, greater emotional resilience, and an increasing ability to see and respond to the dignity and potential in students, patients, or clients. For people who have had traumatic or difficult childhoods, we hypothesize that repeated practice over time will lead to a growing capacity to identify simple caring moments from a diverse range of people, beings and settings in their life. ${ }^{3}$ In SCT workshops, people have reported such experiences anecdotally (e.g., Makransky, 2011, 2012b), but further empirical research is needed to test these claims. We also hypothesize that the receptive mode of SCT can strengthen other forms of meditation, just as attachment priming increases the likelihood that first-time meditators will continue a mindfulness practice (Rowe, Shepstone, Carnelley, Cavanagh, \& Millings, 2016) and just as secure attachment facilitates selfcompassion (Pepping, Davis, O'Donovan, \& Pal, 2015). Finally, we hypothesize that these practices will support a relational identity in which one experiences oneself as part of a larger, interconnected field, yielding psychological resilience and well-being that emerge from selftranscendent experiences such as awe (Stellar et al., 2017), common humanity (Neff, Rude, \& Kirkpatrick, 2007), and humility (Tangney, 2000).

The relational starting point as a pattern for developing compassion and healthy states of mind is not unique to Buddhist traditions; analogous patterns are present in Christian and other contemplative traditions (Dreitcer, 2017; F. Rogers, 2015; Spezio, 2016) and in secular approaches to mental health. In the Circle of Security intervention, for example, therapists act as a secure base from which parents learn to explore their own attachment histories and core sensitivities, so parents can learn to participate in and become an extension of a relational field (Powell, Cooper, Hoffman, \& Marvin, 2014). Compassion-Focused Therapy emphasizes a flow of compassion from others to self, self to self, and self to other (Gilbert, 2014). The ideal parent figure protocol guides people to construct an idealized parent figure and visualize their supportive presence as an adjunct to psychotherapy (Brown \& Elliott, 2016). Generally, the model of the therapist as a secure base is foundational to therapeutic relationships in psychotherapy (e.g., Bowlby, 1988; Holmes \& Slade, 2018; C. R. Rogers, 1957). These diverse presentations that move from receiving to extending care suggest that the relational starting point to compassion training can be tailored for a diversity of specific populations and contexts.

The secular space created for scientific application of compassion training has been called a "closed" secular space, meaning that people's particular spiritual, religious, and cultural worldviews are not invited into the conversation. A shared space is constructed by excluding religious and spiritual perspectives and concerns that would distract from shared scientific principles that everyone can agree to. In contrast, an "open" secular space invites people to draw on their own particular spiritual, religious, and cultural worldviews together with scientific principles to inform their way of engaging the meditations (Lavelle, 2016; Makransky, 2012b). SCT constructs an open secular space by drawing on patterns that can be found across diverse spiritual frameworks and worldviews. This allows practitioners with a wide variety of backgrounds to engage with contemplative practices more fully than is possible in closed secular spaces where the relevance of peoples' particular worldviews for cultivating compassion is not engaged (Lavelle, 2016; Makransky, 2012b). For people practicing in various spiritual traditions, the patterns of SCT can map right onto their own spiritual worldviews. For non-religious people, the same patterns of SCT can map onto secular forms of understanding the relational development of care-as in in attachment theory, social baseline theory (Coan \& Sbarra, 2015), anthropology 
(Hrdy, 2009), moral philosophy (Nussbaum, 1996) and so forth.

\section{Coda}

If meditation techniques continue to proliferate without a relational starting point, we expect people will struggle to cultivate increasingly inclusive, unconditional and sustainable compassion. Data from diverse areas of psychology make clear that relationality is the starting point for humans, and it remains a fundamental need throughout the lifespan. The theoretical frameworks and vocabulary from psychology are a major ally that can help recover important elements of traditional contemplative practices and inform their adaptations into forms that meet the unique needs of participants in modern cultures, and thereby overcome critical barriers to inclusive and sustainable compassion. In addition to the inner psychological barriers reviewed in this paper, we hypothesize that meditation programs empowered by a relational starting point can provide support for addressing systemic barriers as well. In closing, we offer some speculations on this possibility.

In recent years, scholars have criticized secularized mindfulness meditation practices on the grounds that these practices fail to attend to systemic causes of suffering. On one view, individualistic mindfulness practices endorse the assumption that people have individual freedom in choosing how to respond, manage negative emotion, and engage in self-care regardless of external circumstances. Because of these assumptions, mindfulness practices might encourage passive acceptance of oppressive institutional and social structures, rather than critical analysis of them (Purser, 2019). On a different view, a growing movement of meditation teachers and communities combine mindfulness and other contemplative practices with anti-oppression and social activism (see Gleig, 2019, pp. 139-175 for a review of programs that integrate discussions of racism and structural inequity with meditation; see also Magee, 2019; Manuel, 2015; Menakem, 2017; King, 2018; Yang, 2017; williams, Owens, \& Syedullah, 2016).
Informed by interviews with meditation practitioners who identify as people of color, Gleig identified three key ways in which meditation might foster critical engagement and the undoing of structural inequality (Gleig, 2019). First, contemplative practices can help people become more conscious of embodied conditioned defenses and heal the pain of internalized systemic conditioning. Second, such practices might also offer a tool that increases the ability to tolerate and confront the discomfort that is generated by conversations around racism and privilege. Third, within meditation groups, the combination of contemplative practice with explicit discussion of political and social issues can help create a more inclusive communal practice setting that deconstructs the individualism that has been reinforced by Buddhist modernism and re-construct a recognition of ontological interdependence. Finally, the presence of communal support and affinity space within meditation settings could foster increasing sense of safety, relaxation, and the capacity to relate to others beyond reductive impressions that have been conditioned by larger systemic structures.

Similarly, we hypothesize that a relational starting point may enhance efforts to undo structural and systemic barriers to care. A relational starting point can empower this process through the bioenergetic resources that are conveyed by social connection in line with social baseline theory and attachment theory. In an oppressive environment, relationality could provide the psychological resources that allow people to process painful experiences and the potential to challenge oppression effectively. We hypothesize that meditation informed by a relational starting point can help people learn to draw on experiences of care and connection from one's own life, and through such care learn to become compassionately present to one's own feelings and reactions, which brings out powers of inner safeness, equanimity, wisdom, resilience, stability, courage and responsiveness that can empower one to challenge things more effectively, with care and compassion for all involved. Finally, the emphasis on a relational starting point should 
foster a relational ending point, in which the very purpose of training in inclusive care and compassion is to empower one's ability to relate to the fuller humanity in all others, and see through the reductive, limiting impressions of ourselves and others that have been so deeply conditioned by systems of power and economic structures. Influential leaders and social activists, such as Mohandas Gandhi, Martin Luther King Jr., Dorothy Day, Desmond Tutu, and the $14^{\text {th }}$ Dalai Lama all embodied in their lives and work a sustaining and inclusive power of compassion that was first established within the unlimited secure base of their own relational fields. That stable core of security supported their indomitable efforts to address some of the most difficult social problems of our time. Such figures model an exciting possibility for the rest of us that awaits further inquiry and empirical research.

\section{Notes}

1 Although emotional exhaustion and lack of self-efficacy are distinct reasons why people avoid empathy, diverse affective and cognitive facets are likely intertwined in acts of prosocial behavior in ordinary life (Zaki \& Ochsner, 2012). In support of the latter view, research has demonstrated that self-efficacy partially mediates an increase in compassion for an increasing number of others in need, suggesting additional psychological processes at play (Lim \& DeSteno, 2019). Aversive feelings that accompany one's perception of lacking self-efficacy may also contribute to empathic distress.

2 Our emphasis on receptive and extending modes of care parallels three aspects of relationality discussed in the compassion training programs developed by Andrew Dreitcer and Frank Rogers from Christian practices (Dreitcer, 2017).

3 In some cases, people with traumatic interpersonal experiences may find extending mode or deepening mode practices to be an easier entry point to SCT. Over time, familiarization with those modes may facilitate practice of receptive mode. Alternatively, in some cases, people may benefit from psychotherapy before attempting SCT. In any case, at some point, in the trajectory of each person's development, we hypothesize that something like the receptive mode, such as a supportive connection with a therapist, will need to be engaged to generate sustainable, inclusive, and unconditional care (cf., Slade, 2016). We hypothesize this is necessary to establish an unlimited secure base.

\section{Acknowledgments}

We thank Gaëlle Desbordes, Andy Dreitcer, Lisa Flook, June Gruber, Kent Hoffman, Ana Hristić, Molly Kretchmar-Hendricks, Dan Lim, Brian Robinette, Jessie Stern, and two anonymous reviewers for input on an earlier version of this paper.

\section{References}

Allen, K. M., Blascovich, J., Tomaka, J., \& Kelsey, R. M. (1991). Presence of human friends and pet dogs as moderators of autonomic responses to stress in women. Journal of Personality and Social Psychology, 61, 582-589.

Baldwin, M. W. (1992). Relational schemas and the processing of social information. Psychological Bulletin, 112, 461-484.

Barrett, L. F. (2017). How emotions are made: The secret life of the brain. New York, NY: Houghton Mifflin.

Barsalou, L. W. (2008). Grounded cognition. Annual Review of Psychology, 59, 617-645.

Barsalou, L. W. (2016). Situated conceptualization offers a theoretical account of social priming. Current Opinion in Psychology, 12, 6-11.

Batson, C. D. (2011). Altruism in bumans. New York, NY, US: Oxford University Press.

Beckes, L., \& Coan, J. A. (2011). Social baseline theory: The role of social proximity in emotion and economy of action. Social and Personality Psychology Compass, 5, 976-988.

Berger, R., Brenick, A., \& Tarrasch, R. (2018). Reducing Israeli-Jewish Pupils' Outgroup Prejudice with a Mindfulness and CompassionBased Social-Emotional Program. Mindfulness, 9, 1768-1779.

Bernstein, A., Hadash, Y., Lichtash, Y., Tanay, G., Shepherd, K., \& Fresco, D. M. (2015). Decentering and Related Constructs: A Critical Review and Metacognitive Processes Model. Perspectives on Psychological Science, 10, 599-617.

Boag, E. M., \& Carnelley, K. B. (2016). Attachment and prejudice: The mediating role of empathy. British Journal of Social Psychology, 55, 337-356.

Bretherton, I., \& Munholland, K. A. (2016). The internal working model construct in light of 
contemporary neuroimaging research. In J. Cassidy \& P. R. Shaver (Eds.), Handbook of attachment: Theory, research, and clinical applications (3rd ed., pp. 63-88). New York , NY: Guilford Press.

Brown, S. L., Smith, D. M., Schulz, R., Kabeto, M. U., Ubel, P. A., Poulin, M., ... Langa, K. M. (2009). Caregiving Behavior Is Associated With Decreased Mortality Risk. Psychological Science, 20, 488-494.

Buddhaghosa, B. (1975). The path of purification: Visuddhimagga. Kandy, Sri Lanka: Buddhist Publication Society.

Cagney, K. A., Sterrett, D., Benz, J., \& Tompson, T. (2016). Social Resources and Community Resilience in the Wake of Superstorm Sandy. PLOS ONE, 11, e0160824.

Cameron, C. D., Harris, L. T., \& Payne, B. K. (2016). The Emotional Cost of Humanity: Anticipated Exhaustion Motivates Dehumanization of Stigmatized Targets. Social Psychological and Personality Science, 7, 105-112.

Cameron, C. D., Hutcherson, C. A., Ferguson, A. M., Scheffer, J. A., Hadjiandreou, E., \& Inzlicht, M. (2019). Empathy is hard work: People choose to avoid empathy because of its cognitive costs. Journal of Experimental Psychology: General, 148, 962-976.

Cameron, C. D., \& Payne, B. K. (2011). Escaping affect: How motivated emotion regulation creates insensitivity to mass suffering. Journal of Personality and Social Psychology, 100, 1-15.

Cassidy, J., Stern, J. A., Mikulincer, M., Martin, D. R., \& Shaver, P. R. (2018). Influences on Care for Others: Attachment Security, Personal Suffering, and Similarity Between Helper and Care Recipient. Personality and Social Psychology Bulletin, 44, 574-588.

Cikara, M., Bruneau, E. G., \& Saxe, R. R. (2011). Us and Them: Intergroup Failures of Empathy. Current Directions in Psychological Science, 20, 149153.

Cikara, M., Bruneau, E., Van Bavel, J. J., \& Saxe, R. (2014). Their pain gives us pleasure: How intergroup dynamics shape empathic failures and counter-empathic responses. Journal of Experimental Social Psychology, 55, 110-125.
Coan, J. A., \& Sbarra, D. A. (2015). Social Baseline Theory: The social regulation of risk and effort. Current Opinion in Psychology, 1, 8791.

Coan, J. A., Schaefer, H. S., \& Davidson, R. J. (2006). Lending a Hand: Social Regulation of the Neural Response to Threat. Psychological Science, 17, 1032-1039.

Cohen, S. (2004). Social Relationships and Health. American Psychologist, 59, 676-684.

Collins, N. L., \& Feeney, B. C. (2000). A safe haven: An attachment theory perspective on support seeking and caregiving in intimate relationships. Journal of Personality and Social Psychology, 78, 1053-1073.

Collins, N. L., \& Feeney, B. C. (2004). Working Models of Attachment Shape Perceptions of Social Support: Evidence From Experimental and Observational Studies. Journal of Personality and Social Psychology, 87, 363-383.

Collins, N. L., \& Read, S. J. (1994). Cognitive representations of attachment: The structure and function of working models. In Advances in Personal Relationships, Vol. 5. Attachment processes in adulthood (pp. 53-90). London, England: Jessica Kingsley Publishers.

Condon, P. (2014). Cultivating compassion: The effects of compassion- and mindfulness-based meditation on pro-social mental states and behavior. (Doctoral Dissertation). Northeastern University, Boston, MA.

Condon, P. (2017). Mindfulness, compassion, and prosocial behavior. In J. C. Karremans \& E. K. Papies (Eds.), Mindfulness in Social Psychology (pp. 124-138). New York, NY: Routledge.

Condon, P. (2019). Meditation in context: Factors that facilitate prosocial behavior. Current Opinion in Psychology, 28, 15-19.

Condon, P., Desbordes, G., Miller, W. B., \& DeSteno, D. (2013). Meditation Increases Compassionate Responses to Suffering. Psychological Science, 24, 2125-2127.

Dev, V., Fernando, A. T., Kirby, J. N., \& Consedine, N. S. (2019). Variation in the barriers to compassion across healthcare training and disciplines: A cross-sectional study of doctors, nurses, and medical students. International Journal of Nursing Studies, 90, 1-10. 
Dreitcer, A. (2017). Living compassion: Loving like Jesus. Nashville, TN: Upper Room Publishers.

Dykas, M. J., \& Cassidy, J. (2011). Attachment and the processing of social information across the life span: Theory and evidence. Psychological Bulletin, 137, 19-46.

Ehrlich, K. B., Miller, G. E., \& Chen, E. (2016). Childhood Adversity and Adult Physical Health. In Developmental Psychopathology (pp. 142). American Cancer Society.

Eisenberger, N. I., Master, S. L., Inagaki, T. K., Taylor, S. E., Shirinyan, D., Lieberman, M. D., \& Naliboff, B. D. (2011). Attachment figures activate a safety signal-related neural region and reduce pain experience. Proceedings of the National Academy of Sciences, 108, 11721-11726.

Feeney, B. C., \& Collins, N. L. (2001). Predictors of caregiving in adult intimate relationships: An attachment theoretical perspective. Journal of Personality and Social Psychology, 80, 972-994.

Feeney, B. C., \& Collins, N. L. (2015). A New Look at Social Support: A Theoretical Perspective on Thriving Through Relationships. Personality and Social Psychology Review, 19, 113-147.

Feeney, B. C., \& Collins, N. L. (2019). The importance of relational support for attachment and exploration needs. Current Opinion in Psychology, 25, 182-186.

Gelman, S. A. (2004). Psychological essentialism in children. Trends in Cognitive Sciences, 8, 404409.

Gilbert, P. (2014). The origins and nature of compassion focused therapy. British Journal of Clinical Psychology, 53, 6-41.

Gilbert, P. (2019). Explorations into the nature and function of compassion. Current Opinion in Psychology, 28, 108-114.

Gilbert, P., \& Irons, C. (2004). A pilot exploration of the use of compassionate images in a group of self critical people. Memory, 12, 507-516.

Gilbert, P., McEwan, K., Matos, M., \& Rivis, A. (2011). Fears of compassion: Development of three self-report measures. Psychology and Psychotherapy: Theory, Research and Practice, 84, 239-255.

Gillath, O., \& Karantzas, G. (2019). Attachment security priming: A systematic review. Current
Opinion in Psychology, 25, 86-95.

Gillath, O., Selcuk, E., \& Shaver, P. R. (2008). Moving Toward a Secure Attachment Style: Can Repeated Security Priming Help? Social and Personality Psychology Compass, 2, 1651-1666.

Gleig, A. (2019). American dharma: Buddhism beyond modernity. New Haven, CT: Yale University Press.

Goetz, J. L., Keltner, D., \& Simon-Thomas, E. (2010). Compassion: An Evolutionary Analysis and Empirical Review. Psychological Bulletin, 136, 351-374.

Hayes, A. (2004). Acceptance and commitment therapy, relational frame theory, and the third wave of behavioral and cognitive therapies. Behavior Therapy, 35, 639-665.

Holmes, J., \& Slade, A. (2018). Attachment in therapentic practice. Thousand Oaks, CA: Sage Publications, Inc.

Holt-Lunstad, J., Smith, T. B., \& Layton, J. B. (2010). Social Relationships and Mortality Risk: A Meta-analytic Review. PLOS Medicine, 7, e1000316.

Hrdy, S. B. (2009). Mothers and others: The evolutionary origins of mutual understanding. Cambridge, MA: Harvard University Press.

Jazaieri, H., Jinpa, G. T., McGonigal, K., Rosenberg, E. L., Finkelstein, J., SimonThomas, E., ... Goldin, P. R. (2013). Enhancing compassion: A randomized controlled trial of a compassion cultivation training program. Journal of Happiness Studies, 14, 1113-1126.

Jazaieri, H., McGonigal, K., Jinpa, T., Doty, J. R., Gross, J. J., \& Goldin, P. R. (2014). A randomized controlled trial of compassion cultivation training: Effects on mindfulness, affect, and emotion regulation. Motivation and Emotion, 38, 23-35.

Jinpa, T. (2015). A fearless heart: How the courage to be compassionate can transform our lives. New York, NY: Hudson Street Press.

Karremans, J. C., Heslenfeld, D. J., van Dillen, L. F., \& Van Lange, P. A. M. (2011). Secure attachment partners attenuate neural responses to social exclusion: An fMRI investigation. International Journal of Psychophysiology, 81, 44-50. 
King, R. (2018). Mindful of race: Transforming racism from the inside out. Boulder, CO: Sounds True.

King, T. E., \& Wheeler, M. B. (2004). Inequality in health care: Unjust, inhumane, and unattended! Annals of Internal Medicine, 141, 815.

Kirby, J. N., Day, J., \& Sagar, V. (2019). The 'Flow' of compassion: A meta-analysis of the fears of compassion scales and psychological functioning. Clinical Psychology Review, 70, 26-39.

Klimecki, O. M., Leiberg, S., Ricard, M., \& Singer, T. (2014). Differential pattern of functional brain plasticity after compassion and empathy training. Social Cognitive and Affective Neuroscience, 9, 873-879.

Kogut, T., \& Kogut, E. (2013). Exploring the relationship between adult attachment style and the identifiable victim effect in helping behavior. Journal of Experimental Social Psychology, 49, 651-660.

Lavelle, B. D. (2016). Against One Method: Contemplation in Context. In R. E. Purser, D. Forbes, \& A. Burke (Eds.), Handbook of Mindfulness: Culture, Context, and Social Engagement (pp. 233-242). Cham: Springer International Publishing.

Lavelle, B. D. (2017). Compassion in context: Tracing the Buddhist roots of secular, compassion-based contemplative programs. In E. M. Seppala, E. Simon-Thomas, S. L. Brown, M. C. Worline, C. D. Cameron, \& J. R. Doty (Eds.), The Oxford handbook of compassion science (pp. 17-25). New York , NY: Oxford University Press.

Lim, D., \& DeSteno, D. (2016). Suffering and compassion: The links among adverse life experiences, empathy, compassion, and prosocial behavior. Emotion, 16, 175-182.

Lim, D., \& DeSteno, D. (2019). Past adversity protects against the numeracy bias in compassion. Emotion. https://doi.org/10.1037/emo0000655

Lutz, A., Jha, A. P., Dunne, J. D., \& Saron, C. D. (2015). Investigating the phenomenological matrix of mindfulness-related practices from a neurocognitive perspective. The American Psychologist, 70, 632-658.

Magee, R. V. (2019). The inner work of racial justice: Healing ourselves and transforming our communities through mindfulness. New York, NY: Penguin Random House.

Makransky, J. (1998). Buddhahood embodied: Sources of controversy in India and Tibet. Delhi, India: Sri Satguru Publications.

Makransky, J. (2007). Awakening through love. Somerville, MA: Wisdom Publications.

Makransky, J. (2011). Compassion beyond fatigue: Contemplative training for people who serve others. In J. Simmer-Brown \& F. Grace (Eds.), Meditation and the classroom (pp. 85-94). Albany, NY: SUNY Press.

Makransky, J. (2012a). Compassion in Buddhist psychology. In C. K. Germer \& R. D. Siegel (Eds.), Wisdom and compassion in psychotherapy: Deepening mindfulness in clinical practice (pp. 6174). New York , NY: Guilford Press.

Makransky, J. (2012b). How contemporary Buddhist practice meets the secular world in its search for a deeper grounding for service and social action. Dharma World, (April-June). Retrieved from https://rkworld.org/dharmaworld/dw_2012aprjunebudd histpractice.aspx

Makransky, J. (2019). Sustainable Compassion Training (SCT) Protocol. Unpublished.

Mandalaywala, T. M., Amodio, D. M., \& Rhodes, M. (2018). Essentialism Promotes Racial Prejudice by Increasing Endorsement of Social Hierarchies. Social Psychological and Personality Science, 9, 461-469.

Manuel, Z. E. (2015). The way of tenderness: Awakening through race, sexuality, and gender. Somerville, MA: Wisdom Publications.

Maslach, C., Schaufeli, W. B., \& Leiter, M. P. (2001). Job Burnout. Annual Review of Psychology, 52, 397-422.

McMahan, D. L. (2002). Empty vision: Metaphor and visionary imagery in Mahayana Buddhism. New York, NY: Routledge.

McMahan, D. L. (2008). The making of Buddhist modernism. New York, NY: Oxford University Press.

Menakem, R. (2017). My grandmother's hands: Racialized trauma and the pathway to mending our hearts and bodies. Las Vegas, NV: Central Recovery Press.

Mikulincer, M., \& Florian, V. (1995). Appraisal of 
and Coping with a Real-Life Stressful Situation: The Contribution of Attachment Styles. Personality and Social Psychology Bulletin, 21, 406414.

Mikulincer, M., \& Shaver, P. R. (2001). Attachment theory and intergroup bias: Evidence that priming the secure base schema attenuates negative reactions to out-groups. Journal of Personality and Social Psychology, 81, 97115.

Mikulincer, M., \& Shaver, P. R. (2005). Attachment Security, Compassion, and Altruism. Current Directions in Psychological Science, 14, 34-38.

Mikulincer, M., \& Shaver, P. R. (2007). Boosting Attachment Security to Promote Mental Health, Prosocial Values, and Inter-Group Tolerance. Psychological Inquiry, 18, 139-156.

Mikulincer, M., \& Shaver, P. R. (2015). Boosting attachment security in adulthood: The "broaden-and-build" effects of securityenhancing mental representations and interpersonal contexts. In J. A. Simpson \& W. S. Rholes (Eds.), Attachment theory and research: New directions and emerging themes (pp. 124-144). New York, NY: Guilford.

Mikulincer, M., Shaver, P. R., Bar-On, N., \& Sahdra, B. K. (2014). Security enhancement, self-esteem threat, and mental depletion affect provision of a safe haven and secure base to a romantic partner. Journal of Social and Personal Relationships, 31, 630-650.

Mikulincer, M., Shaver, P. R., Gillath, O., \& Nitzberg, R. A. (2005). Attachment, Caregiving, and Altruism: Boosting Attachment Security Increases Compassion and Helping. Journal of Personality and Social Psychology, 89, 817-839.

Mikulincer, M., Shaver, P. R., Sahdra, B. K., \& Bar-On, N. (2013). Can security-enhancing interventions overcome psychological barriers to responsiveness in couple relationships? Attachment \& Human Development, 15, 246-260.

Nanamoli, B., \& Bodhi, B. (Eds.). (1995). The middle length discourses of the Buddha: A translation of the majjhima nikaya. Somerville, MA: Wisdom Publications.
Neff, K. D., Rude, S. S., \& Kirkpatrick, K. L. (2007). An examination of self-compassion in relation to positive psychological functioning and personality traits. Journal of Research in Personality, 41, 908-916.

Norman, L., Lawrence, N., Iles, A., Benattayallah, A., \& Karl, A. (2015). Attachment-security priming attenuates amygdala activation to social and linguistic threat. Social Cognitive and Affective Neuroscience, 10, 832-839.

Nussbaum, M. (1996). Compassion: The basic social emotion. Social Philosophy and Policy, 13, 27-58.

Pace, T. W. W., Negi, L. T., Adame, D. D., Cole, S. P., Sivilli, T. I., Brown, T. D., ... Raison, C. L. (2009). Effect of compassion meditation on neuroendocrine, innate immune and behavioral responses to psychosocial stress. Psychoneuroendocrinology, 34, 87-98.

Pace, T. W. W., Negi, L. T., Dodson-Lavelle, B., Ozawa-de Silva, B., Reddy, S. D., Cole, S. P., ... Raison, C. L. (2013). Engagement with Cognitively-Based Compassion Training is associated with reduced salivary C-reactive protein from before to after training in foster care program adolescents. Psychoneuroendocrinology, 38, 294-299.

Paris, M., \& Hoge, M. A. (2010). Burnout in the mental health workforce: A review. The Journal of Behavioral Health Services \& Research, 37, 519528.

Pepping, C. A., Davis, P. J., O’Donovan, A., \& Pal, J. (2015). Individual differences in selfcompassion: the role of attachment and experiences of parenting in childhood. Self and Identity, 14, 104-117.

Pietromonaco, P. R., Uchino, B., \& Dunkel Schetter, C. (2013). Close relationship processes and health: Implications of attachment theory for health and disease. Health Psychology, 32, 499-513.

Powell, B., Cooper, G., Hoffman, K., \& Marvin, B. (2014). The circle of security intervention. New York, NY: Guilford Press.

Purser, R. E. (2019). McMindfulness. London, England: Repeater Books.

Purser, R. E., Forbes, D., \& Burke, A. (Eds.). (2016). Handbook of mindfulness: Culture, context, 
and social engagement. Switzerland: Springer International Publishing.

Ricard, M. (2015). Altruism: The power of compassion to change yourself and the world. New York, NY: Little, Brown and Company.

Rockliff, H., Gilbert, P., McEwan, K., Lightman, S., \& Glover, D. (2008). A pilot exploration of heart rate variability and salivary cortisol responses to compassion-focused imagery. Clinical Neuropsychiatry, 5, 132-139.

Roeser, R. W., Colaianne, B. A., \& Greenberg, M. A. (2018). Compassion and human development: current approaches and future directions. Research in Human Development, 15, 238-251.

Rogers, C. R. (1957). The necessary and sufficient conditions of therapeutic personality change. Journal of Consulting Psychology, 21, 95-103.

Rogers, F. (2015). Practicing compassion. Nashville, TN: Fresh Air Books.

Ronen, S., \& Mikulincer, M. (2012). Predicting employees' satisfaction and burnout from managers' attachment and caregiving orientations. European Journal of Work and Organizational Psychology, 21, 828-849.

Rothschild, B. (2006). Help for the helper: The psychophysiology of compassion fatigue and vicarious trauma. New York, NY, US: W W Norton \& Co.

Rowe, A. C., Shepstone, L., Carnelley, K. B., Cavanagh, K., \& Millings, A. (2016). Attachment security and self-compassion priming increase the likelihood that first-time engagers in mindfulness meditation will continue with mindfulness training. Mindfulness, 7, 642-650.

Samuel, G. (2012). Introducing Tibetan Buddhism. New York, NY: Routledge. ntideva. (1997). The way of the bodhisattva. Boston, MA: Shambhala Publications.

Schnall, S., Roper, J., \& Fessler, D. M. T. (2010). Elevation leads to altruistic behavior. Psychological Science, 21, 315-320.

Schumann, K., Zaki, J., \& Dweck, C. S. (2014). Addressing the empathy deficit: Beliefs about the malleability of empathy predict effortful responses when empathy is challenging. Journal of Personality and Social Psychology, 107, 475-493.
Sharma, E., \& Morwitz, V. G. (2016). Saving the masses: The impact of perceived efficacy on charitable giving to single vs. multiple beneficiaries. Organizational Behavior and Human Decision Processes, 135, 45-54.

Shaver, P. R., Lavy, S., Saron, C. D., \& Mikulincer, M. (2007). Social Foundations of the Capacity for Mindfulness: An Attachment Perspective. Psychological Inquiry, 18, 264-271.

Shaver, P. R., Mikulincer, M., \& Cassidy, J. (2019). Attachment, caregiving in couple relationships, and prosocial behavior in the wider world. Current Opinion in Psychology, 25, 16-20.

Shonin, E., Gordon, W. V., Compare, A., Zangeneh, M., \& Griffiths, M. D. (2015). Buddhist-Derived Loving-Kindness and Compassion Meditation for the Treatment of Psychopathology: A Systematic Review. Mindfulness, 6, 1161-1180.

Simpson, J. A., Rholes, W. S., \& Nelligan, J. S. (1992). Support seeking and support giving within couples in an anxiety-provoking situation: The role of attachment styles. Journal of Personality and Social Psychology, 62, 434-446.

Slade, A. (2016). Attachment and adult psychotherapy: Theory, research, and practice. In J. Cassidy \& P.R. Shaver (Eds.), Handbook of attachment: Theory, research, and clinical applications, $3^{\text {rd }}$ ed. (759-779). New York, NY: Guilford Press.

Slovic, P. (2010). If I look at the mass I will never act: Psychic numbing and genocide. In S. Roeser (Ed.), Emotions and Risky Technologies (pp. 37-59). Dordrecht: Springer Netherlands.

Smith, T. W., Ruiz, J. M., \& Uchino, B. N. (2004). Mental activation of supportive ties, hostility, and cardiovascular reactivity to laboratory stress in young men and women. Health Psychology, 23, 476-485.

Spezio, M. (2016). Forming identities in grace: Imitatio and habitus as contemporary categories for the sciences of mindfulness and virtue. Ex Auditu, 32, 125-141.

Stellar, J. E., Gordon, A. M., Piff, P. K., Cordaro, D., Anderson, C. L., Bai, Y., ... \& Keltner, D. (2017). Self-transcendent emotions and their social functions: Compassion, gratitude, and awe bind us to others through prosociality. 
Emotion Review, 9, 200-207.

Tajfel, H., \& Turner, J. C. (2004). The Social Identity Theory of Intergroup Behavior. In J. T. Jost \& J. Sidanius (Eds.), Political psychology (pp. 276-293). New York, NY: Psychology Press.

Tangney, J. P. (2000). Humility: Theoretical perspectives, empirical findings and directions for future research. Journal of Social and Clinical Psychology, 19, 70-82.

Tarrasch, R., Berger, R., \& Grossman, D. (2020). Mindfulness and compassion as key factors in improving teacher's well being. Mindfulness. Published online February 10, 2020.

Thompson, E. (2020). Why I am not a Buddhist. New Haven, CT: Yale University Press.

Thondup, T. (1996). The healing power of mind. Boston, MA: Shambhala Publications.

Treleaven, D. A. (2018). Trauma-sensitive mindfulness: Practices for safe and transformative bealing. New York, NY: W. W. Norton \& Co.

Tsoknyi Rinpoche. (2012). Open heart, open mind. New York, NY: Harmony Books.

Van Bavel, J. J., Packer, D. J., \& Cunningham, W. A. (2008). The Neural Substrates of In-Group Bias: A Functional Magnetic Resonance Imaging Investigation. Psychological Science, 19, 1131-1139.

Varela, F. J. (1999). Ethical know-how: Action, wisdom, and cognition. Stanford, CA: Stanford University Press.
Vitaliano, P. P., Zhang, J., \& Scanlan, J. M. (2003). Is caregiving hazardous to one's physical health? A meta-analysis. Psychological Bulletin, 129, 946-972.

Waters, H. S., \& Waters, E. (2006). The attachment working models concept: Among other things, we build script-like representations of secure base experiences. Attachment \& Human Development, 8, 185-197.

Waters, T. E., \& Roisman, G. I. (2019). The secure base script concept: An overview. Current Opinion in Psychology, 25, 162-166.

Waytz, A., \& Epley, N. (2012). Social connection enables dehumanization. Journal of Experimental Social Psychology, 48, 70-76.

Wilkinson, R., \& Pickett, K. (2020). The inner level: How more equal societies reduce stress, restore sanity and improve everyone's well-being. New York, NY: Penguin Books.

williams, a. K., Owens, R., \& Syedullah, J. (2016). Radical dharma: Talking race, love, and liberation. Berkeley, CA: North Atlantic Books.

Yang, L. (2017). Awakening together: The spiritual practice of inclusivity and community. Somerville, MA: Wisdom Publications.

Zhang, H., Chan, D. K.-S., Teng, F., \& Zhang, D. (2015). Sense of interpersonal security and preference for harsh actions against others: The role of dehumanization. Journal of Experimental Social Psychology, 56, 165-171. 